\title{
Influence of genetic discrimination perceptions and knowledge on cancer genetics referral practice among clinicians
}

Katrina J. Lowstuter, $M S^{1}$, Sharon Sand, $B A^{1}$, Kathleen R. Blazer, $M S^{1}$, Deborah J. MacDonald, $P h D^{1}$, Kimberly C. Banks, MS ${ }^{1}$, Carol A. Lee, JD', Barbara U. Schwerin, Esq ${ }^{3}$, Margaret Juarez, $M D^{4}$, Gwen C. Uman, PhD , and Jeffrey N. Weitzel, $M D^{1}$

\begin{abstract}
Purpose: To describe nongenetics clinicians' perceptions and knowledge of cancer genetics and laws prohibiting genetic discrimination, attitudes toward the use of cancer genetic testing, and referral practices. Methods: Invitations to participate were sent to a random stratified sample of California Medical Association members and to all members of California Association of Nurse Practitioners and California Latino Medical Association. Responders in active practice were eligible and completed a 47-item survey. Results: There were 1181 qualified participants (62\% physicians). Although $96 \%$ viewed genetic testing as beneficial for their patients, $75 \%$ believed fear of genetic discrimination would cause patients to decline testing. More than $60 \%$ were not aware of federal or California laws prohibiting health insurance discrimination-concern about genetic discrimination was selected as a reason for nonreferral by $11 \%$. A positive attitude toward genetic testing was the strongest predictor of referral (odds ratio: 3.55 [95\% confidence interval: 2.24-5.63], $P<0.001$ ) in stepwise logistic regression analyses. The higher the belief in genetic discrimination, the less likely a participant was to refer (odds ratio: 0.72 [95\% confidence interval: 0.518-0.991], $P<0.05$ ), whereas more knowledge of genetic discrimination law was associated with comfort recommending (odds ratio: 1.18 [95\% confidence interval: 1.11-1.25], $P<0.001$ ) and actual referral (odds ratio: 3.55 [95\% confidence interval: $2.24-5.63$ ], $P<0.001$ ). Conclusion: Concerns about genetic discrimination and knowledge deficits may be barriers to cancer genetics referrals. Clinician education may help promote access to cancer screening and prevention. Genet Med 2008:10(9):691-698.
\end{abstract}

Key Words: cancer genetics, education, genetic discrimination, genetic testing, health insurance, insurance discrimination, physician, nurse practitioner

Genetic cancer risk assessment (GCRA) is a process that includes genetic counseling and testing to assess an individual/ family's cancer risks, and to guide screening and prevention efforts. Cancer predisposition testing has become standard of care for numerous heritable cancer syndromes (e.g., hereditary breast/ovarian cancer, familial adenomatous polyposis, and multiple endocrine neoplasia). ${ }^{1,2}$ However, perceived potential for genetic discrimination (GD; "discrimination directed against an individual or family based solely on an apparent or

\footnotetext{
From the ${ }^{1}$ Department of Clinical Cancer Genetics, City of Hope, Duarte, California; ${ }^{2} \mathrm{Cal}-$ ifornia Medical Association Foundation, Sacramento, California; ${ }^{3}$ Loyola Law School, Los Angeles, California; ${ }^{4}$ California Latino Medical Association, Los Angeles, California; and ${ }^{5}$ Vital Research, LLC, Los Angeles, California.

Kimberly C. Banks is currently at St. Joseph Hospital, Orange, California.

Jeffrey N. Weitzel, MD, City of Hope, Department of Clinical Cancer Genetics, 1500 East Duarte Road,Duarte, CA 91010.E-mail: jweitzel@coh.org.

Disclosure: The authors declare no conflict of interest.

Submitted for publication March 19, 2008.

Accepted for publication June 13, 2008.

DOI: $10.1097 /$ GIM.0b013e3181837246
}

perceived genetic variation from the 'normal' human genotype") is a barrier to GCRA. ${ }^{3-9}$ Although GD can be subtle, such as social stigma, the major concern is health, life, or disability insurance and/or employment discrimination.

Legislation such as the Health Insurance Portability and Accountability Act (HIPAA) ${ }^{10,11}$ provides some protection in the group health insurance market, and 47 states have passed laws providing varying protection for health, life, and/or disability insurance. ${ }^{12}$ All of the above applies exclusively to asymptomatic genetic traits (e.g., individuals with no personal history of cancer). California was among the earliest (some provisions enacted in 1992) to provide such coverage. In addition, Executive Order 13145, "to prohibit discrimination in federal employment based on genetic information," was signed into law on February 8, 2000. Although in recent rulings the meaning of disability, unrelated to cancer genetics, may have diluted the level of protection, the Americans with Disabilities Act theoretically provides some employment protection for individuals with a genetic predisposition. ${ }^{13}$ The Equal Employment Opportunity Commission action in the Burlington Northern case represented its first Americans with Disabilities Act lawsuit 
challenging an employer's administration of a genetic test in $2001 .{ }^{14}$

Although some studies report instances of GD by health insurance companies, ${ }^{15-17}$ their methodology included nonrepresentative sampling methods, admixture of cases with and without family history, affected and presymptomatic individuals, and cases with and without genetic testing. ${ }^{7,18}$ It is possible that more subtle forms of GD may exist, and the level of protection conferred by respective GD legislation is uncertain absent experience with violations, interpretation, and legal precedent. Nonetheless, to date, there is no case law documenting health insurance discrimination based on presymptomatic GCRA. Yet patients and health care providers perceive a high risk for potential GD despite federal and state protective legislation. ${ }^{5,6,19-22}$ There has been so little documented about actual discrimination, one does not necessarily know how "imperfect" the protections are or are not. This lack of understanding about the existing laws and general mistrust of insurance companies may contribute to an underlying sense of unease about genetic testing.

Clinicians' perceptions and lack of knowledge of cancer genetics and protective legislation may limit access to genetic testing and appropriate cancer risk screening and prevention. ${ }^{19}$ Primary care clinicians are often gatekeepers for access to care, and oncology clinicians also influence GCRA referrals. ${ }^{2}$ Knowledge of protective legislation for clinical cancer genetics and referral patterns has not been previously surveyed. The purpose of this study was to survey nongenetics clinicians (hereafter referred to as "clinicians"), to explore the extent to which knowledge gaps and perceptions about cancer genetics, $\mathrm{GD}$, and protective laws influence cancer genetics referrals.

\section{MATERIALS AND METHODS}

\section{Target population/sampling}

Because state laws regarding GD vary across the country, we restricted eligibility to practicing clinicians in California, a state with relatively comprehensive statutes that have been established for more than 10 years. To enable a cross section of clinicians in California, we generated a sampling frame of (1) random stratified sampling of 1600 physicians from California Medical Association (CMA), including only those from primary care specialties of medical oncology, internal medicine, family medicine, and obstetrics/gynecology; and (2) the membership of nurse practitioners (NP) from the California Association of Nurse Practitioners (CANP). CMA is an advocacy organization that represents more than 30,000 California physicians. At the time of the survey CANP had 2092 members with contact information. To increase minority clinician representation and generalizability of results, the California Latino Medical Association (CaLMA) physician membership of 2524 was sampled, and the CMA database was over-sampled for members $(n=1993)$ practicing in urban zip codes. Enriching for individuals in urban cores also enabled targeting areas where cancer genetics services are available, thus allowing greater opportunity to observe the relationship between knowledge and perceptions of GD and referral behavior.

\section{Instruments}

\section{Survey description}

The study employed a 47-item survey of perceptions, knowledge, and behavioral intent (referral patterns) regarding cancer genetics and GD, along with basic demographics (gender, age, race/ethnicity), practice setting, and patient populations. Ten Likert scale items investigated attitudes and beliefs toward cancer genetic testing and issues of GD: use and benefit of genetic testing (6); confidence in recognizing hereditary cancer patterns (1); insurance issues and GD concerns (3). Seventeen items assessed knowledge: knowledge of protective federal legislation (HIPAA) (4); California state protective legislation (5); cancer genetics knowledge (3); recognition of families appropriate for referral (5).23,24

Respondents who indicated they had not referred patients for genetic counseling were instructed to select reasons for nonreferral from nine choice options. A separate section asked for open-ended description of why they were or were not comfortable referring patients. This section could be mailed separately if desired and contact information could be voluntarily included to facilitate clarification of responses. The survey took approximately 20 minutes to complete.

\section{Survey validity}

Survey items were based on a previously validated pilot study. ${ }^{19}$ The survey underwent revisions by developers and experts from the Cancer Legal Resource Center at Loyola Law School and City of Hope's Cancer Genetics Education Program and Nursing Research and Education faculty. Items were classified into attitudes, behavioral intent, and knowledge categories, and rated and revised for clarity, importance in assessing beliefs, behavioral intent, knowledge, and relevance to GD.

\section{Survey reliability}

Interitem associations within attitude, behavior, and knowledge items were previously examined in a pilot survey $(n=$ 129) and results informed survey revision. ${ }^{19}$ The coefficient alpha values for internal consistency reliability of survey scales derived from data obtained in this study were Genetic Testing Attitudes (three items) 0.65; Attitudes toward Genetic Testing (seven items) 0.78; Overall Knowledge of Cancer Genetics and Discrimination (17 items) 0.71; and Knowledge of Genetic Discrimination (nine items) 0.77 .

\section{Procedures}

Two mechanisms encouraged survey response: (1) incentives of a $\$ 25$ honorarium for physician (MD) respondents and a $\$ 5$ coffee gift card for NP respondents; and (2) a modified version of Dillman response rate methodology. ${ }^{25}$ 


\section{Survey administration}

The survey was deployed as a scannable form, obtained by participant request via a prequalification postcard and returned by mail or fax, and as an online survey. As originally described, the Dillman method consists of a mailed questionnaire followed by a postcard 1 week later, a questionnaire on the third week and a final letter with questionnaire via certified mail after 7 weeks. ${ }^{25}$ We modified the Dillman mailing methodology in two ways: (1) a prequalification postcard was substituted for the survey to minimize response bias based on survey content; and (2) postcard reminders were used for the second through fourth mailings, and a letter on the respective professional association letterhead was used for the final invitation. Because of an estimated overlap of $20-25 \%$ with CMA, CaLMA members were asked to disregard the invitation if they had already completed the survey.

\section{Data analysis}

Data were audited for accuracy and respondents not in active practice were removed. Out of range values were corrected or set to missing. Attitude items were recoded so that high scores represented positive attitudes, and scales were tested for reliability. Knowledge items were scored as correct or incorrect, and knowledge scales were tested for reliability. Data were analyzed using SPSS for Windows, v 15.0 and descriptive statistics were calculated.

Knowledge and attitudes were compared by profession and by age group (under $50 ; 50+$ ) using independent $t$ tests. Oneway analysis of variance was used to examine differences in attitudes and knowledge according to race/ethnicity, work settings, and specialty. Two forward stepwise logistic regression analyses controlling for demographic and practice characteristics in an initial block, were used to identify significant explanatory binary variables of (1) being comfortable referring patients for genetic counseling and (2) actually making referrals. The overall knowledge score was analyzed, and then replaced by the knowledge of GD law for the other analysis. We exclude (from reported referrals analyses) those respondents indicating that they had no opportunity to refer because they had not seen high risk patients, and those indicating that no genetic counseling services were available to them.

Qualitative data were organized by central topic, with overlapping themes placed in the predominant category. Because of the highly public nature of issues surrounding genetics and genetic information, a validity threat log was kept of news items, lay-press, or professional articles that could affect the beliefs, knowledge, and behavior of the population sampled. A review of 1997-1998 lay and professional articles indicated considerable coverage about the HIPAA enacted in 1996. California was one of the first states to enact protections and provided more protection than many other states. A search of professional and trade journals and the Los Angeles Times newspaper archives revealed minimal GD-related publicity during the study period. The survey was completed from November 2004 to December 2006, avoiding some of the major publicity about the recently enacted Genetic Information Nondiscrimination Act (GINA) that occurred during 20072008. Therefore, no contemporary validity threats were noted.

\section{RESULTS}

A total of 1222 clinicians responded to the survey; $98 \%$ were in active practice. Sixteen incomplete surveys and 25 responders no longer practicing were discarded, leaving 1181 valid surveys. The response rate and margin of error was $19.3 \pm 3.3 \%$ for CMA, and $20.3 \pm 4 \%$ for CANP, with 618 valid surveys for CMA and 447 for CANP. Supplemental sampling of CaLMA to increase minority accrual yielded 116 qualified responders. The degree of overlap between the CaLMA and CMA databases is uncertain-survey instructions for the CaLMA members told them to ignore the invitation if they had already responded via CMA. The majority of respondents were CMA members for whom some practice information was available. The intended specialty and practice-type distributions were achieved using proportional random sampling. Respondents were equivalent to CMA members sampled in specialty distribution, but were more likely to be in very large practices (37\%) than were nonrespondents (30\%). In addition, $91 \%$ of respondents practiced within an urban core (based on zip code). Respondents' demographic and practice setting data are displayed in Table 1.

\section{Attitudes/beliefs toward hereditary cancer genetic testing and GD issues}

Table 2 displays responses to cancer genetic testing and insurance discrimination items. The 4-point scale represented in Table 2 represents the answer choices of "strongly agree" (4), "agree," "disagree," and "strongly disagree" (1). Overall, respondents had a positive attitude toward the benefits of genetic testing (3.1 on a 4-point scale, $\mathrm{SD}=0.42$; data not shown) but they tended to perceive that GD exists on questions regarding genetic testing and insurance (mean score 2.3 on a 4-point scale, $\mathrm{SD}=0.57$; data not shown). Three-quarters thought that patients might decline testing because of fear of health insurance discrimination. Slightly more than half thought that testing created health insurance problems for their patients with and without cancer.

\section{Knowledge of cancer genetics and GD law}

Cancer genetics and GD law knowledge outcomes are summarized in Table 3. Half of the respondents knew the correct answer to at least two of the three questions regarding cancer risks for a woman with a $B R C A$ gene mutation. When given five hypothetical family cancer histories, only $30 \%$ correctly identified four or more scenarios as appropriate or inappropriate for genetics referral.

Fewer than $24 \%$ of federal and $34 \%$ of state law questions were answered correctly.

The mean overall knowledge score (combined knowledge of discrimination laws and cancer genetics) was $41 \%$ (Fig. 1). MDs had greater knowledge, on both overall survey questions 
Table 1

Demographics and practice setting

\begin{tabular}{|c|c|c|c|}
\hline Characteristic & $\begin{array}{c}\text { Total, \% } \\
(\mathrm{N}=1181)\end{array}$ & $\begin{array}{l}\mathrm{MD}, \% \\
(\mathrm{n}=734)\end{array}$ & $\begin{array}{c}\mathrm{NP}, \% \\
(\mathrm{n}=447)\end{array}$ \\
\hline \multicolumn{4}{|l|}{ Gender } \\
\hline Female & 52.7 & 26.3 & 95.9 \\
\hline Male & 47.3 & 73.7 & 4.1 \\
\hline Age $<50$ yrs & 37.9 & 35.3 & 42.3 \\
\hline Age $>50$ yrs & 62.1 & 64.7 & 57.7 \\
\hline \multicolumn{4}{|l|}{ Race/ethnicity } \\
\hline $\begin{array}{l}\text { American Indian, Alaska } \\
\text { native/native } \\
\text { Hawaiian, or other } \\
\text { Pacific Islander }\end{array}$ & 1.1 & 0.7 & 1.8 \\
\hline Asian & 17.9 & 23.8 & 8.1 \\
\hline Black/African American & 2.1 & 2.3 & 1.8 \\
\hline White & 66.4 & 57.0 & 82.0 \\
\hline Hispanic/Latino & 12.4 & 16.2 & 6.3 \\
\hline \multicolumn{4}{|l|}{ Practice setting } \\
\hline HMO & 36.7 & 46.4 & 20.8 \\
\hline $\begin{array}{l}\text { Medical school or } \\
\text { research institute }\end{array}$ & 4.1 & 2.3 & 7.0 \\
\hline Private clinic/hospital & 42.5 & 43.5 & 40.9 \\
\hline Public hospital & 8.2 & 4.9 & 13.5 \\
\hline $\begin{array}{l}\text { Community/public } \\
\text { health }\end{array}$ & 5.3 & 2.3 & 10.2 \\
\hline $\begin{array}{l}\text { Student health (college/ } \\
\text { school health) }\end{array}$ & 2.6 & 0.3 & 6.3 \\
\hline Other & 0.7 & 0.3 & 1.4 \\
\hline
\end{tabular}

$\mathrm{MD}$, physician; $\mathrm{NP}$, nurse practitioner.

and on questions specific to GD, than NPs $(P<0.001)$. There were no significant differences in knowledge by race/ethnicity, work setting, or practice specialty, but overall knowledge was significantly greater for respondents in the urban versus rural core $(P=0.012)$. Age data did not show meaningful differences in knowledge $(<50=2.40,50+=2.71)$ or attitudes $(<50=3.09,50+=3.17)$. Few respondents achieved $\geq 80 \%$ correct in the knowledge questions (MDs: $3.8 \%$ [24/722]; NPs: $1.4 \%[6 / 436])$. Of the 30 who scored $>80 \%$ on the knowledge questions the majority were MD (24), white (20), age 50+, practicing in the clinic $>90 \%$ of the time (18), in an urban core (27).

\section{Behavioral intent/practice}

About two-thirds of respondents $(63.3 \%)$ indicated that they were comfortable recommending genetic counseling to patients potentially at high risk for cancer, but only $45 \%$ (532) had done so. The predominant theme among 722 comments describing why respondents were comfortable recommending genetic counseling was the demonstrated clinical use of testing, as evidenced by the following response: "It will identify who needs invasive screening or prophylactic treatment." Among
Table 2

Attitudes and beliefs toward genetic testing and insurance

\begin{tabular}{|c|c|c|}
\hline & Agree $^{a}(\%)$ & Disagree $^{b}(\%)$ \\
\hline \multicolumn{3}{|l|}{ Genetic testing } \\
\hline $\begin{array}{l}\text { Genetic testing offers health benefits to } \\
\text { patients presumed to be at high risk } \\
\text { for cancer }\end{array}$ & 96.8 & 3.2 \\
\hline $\begin{array}{l}\text { Genetic testing offers health benefits to } \\
\text { family members of those patients } \\
\text { who undergo genetic testing }\end{array}$ & 93.7 & 6.3 \\
\hline $\begin{array}{l}\text { Results of genetic testing may reduce } \\
\text { unnecessary cancer screenings }\end{array}$ & 64.5 & 35.5 \\
\hline $\begin{array}{l}\text { Results of genetic testing can guide } \\
\text { decision making about risk } \\
\text { reduction }\end{array}$ & 96.4 & 3.6 \\
\hline $\begin{array}{l}\text { Genetic testing decreases psychological } \\
\text { distress about cancer predisposition } \\
\text { in patients who do not carry a } \\
\text { known family mutation }\end{array}$ & 83.5 & 16.5 \\
\hline $\begin{array}{l}\text { Genetic testing motivates high-risk } \\
\text { patients to take preventive measures }\end{array}$ & 89.4 & 10.6 \\
\hline $\begin{array}{l}\text { I can recognize hereditary family } \\
\text { cancer patterns }\end{array}$ & 68.4 & 31.6 \\
\hline \multicolumn{3}{|l|}{ Genetic testing and insurance } \\
\hline $\begin{array}{l}\text { Genetic testing is likely to be declined } \\
\text { by patients because of fear of health } \\
\text { insurance discrimination }\end{array}$ & 75.3 & 24.7 \\
\hline $\begin{array}{l}\text { Genetic testing creates health } \\
\text { insurance problems (cancellations } \\
\text { and or higher premiums) for my } \\
\text { patients with cancer }\end{array}$ & 52.4 & 47.6 \\
\hline $\begin{array}{l}\text { Genetic testing creates health } \\
\text { insurance problems (cancellations } \\
\text { and or higher premiums) for my } \\
\text { patients without cancer }\end{array}$ & 52 & 48 \\
\hline
\end{tabular}

${ }^{a}$ Responses strongly agree/agree grouped.

${ }^{b}$ Responses disagree/strongly disagree grouped.

the referrers, $37 \%$ stated they have suggested patients pay out of pocket for genetic testing. Of these, $48 \%$ indicated that concern about GD was a reason for suggesting patients pay out of pocket. The two main referral barriers were lack of opportunity and an unclear referral process (Fig. 2).

Frequent themes from 424 comments describing why respondents were not comfortable recommending genetic counseling was regarding the lack of medical evidence to support testing and the lack of referral guidelines. For example:

- "Not sure if it is reliable, how to advise patients on results;"

- "Lack of [referral] guidelines."

Some clinicians reported that they lacked the necessary knowledge base to appropriately identify or advise patients:

- "Don't have the training to know what to order and what the results mean;"

- "I need to do more review, based on questions above." 
Table 3

Knowledge

\begin{tabular}{|c|c|c|c|}
\hline Cancer genetics knowledge & Yes $(\%)$ & No $(\%)$ & Do not know (\%) \\
\hline \multicolumn{4}{|l|}{ A woman with breast cancer who carriers a $B R C A$ gene mutation } \\
\hline Is at an increased risk for developing endometrial cancer & 35.1 & 36.9 & 28.1 \\
\hline Has approximately a $50 \%$ chance of developing contralateral cancer & 74.1 & 5.2 & 20.7 \\
\hline May reduce her risk for contralateral breast cancer if she has her ovaries removed before age 40 & 37.4 & 19.5 & 43.2 \\
\hline \multicolumn{4}{|l|}{ I would advise genetic counseling for the family of a woman without cancer who has } \\
\hline Two siblings diagnosed with colorectal cancer before age 50 & 81.1 & 12.1 & 6.7 \\
\hline A mother diagnosed with breast cancer at age 60 & 19.9 & 72.2 & 7.9 \\
\hline $\begin{array}{l}\text { A maternal aunt diagnosed with breast cancer at age } 57 \text { and a paternal grandmother diagnosed } \\
\text { with breast cancer at age } 59\end{array}$ & 30.9 & 59.0 & 10.2 \\
\hline A paternal aunt diagnosed with breast cancer at age 38 & 49.8 & 39.0 & 11.2 \\
\hline A father diagnosed with breast cancer at age 70 & 29.6 & 52.7 & 17.7 \\
\hline Genetic discrimination law knowledge & True $(\%)$ & False $(\%)$ & Do not know (\%) \\
\hline \multicolumn{4}{|l|}{ The health insurance portability and accountability act of 1996 (HIPAA) } \\
\hline $\begin{array}{l}\text { Prohibits health insurance discrimination in the group insurance market on the basis of genetic } \\
\text { test results }\end{array}$ & 39.0 & 7.6 & 53.5 \\
\hline $\begin{array}{l}\text { Prohibits health insurance discrimination in the individual insurance market on the basis of } \\
\text { genetic test results }\end{array}$ & 22.5 & 17.1 & 60.4 \\
\hline Defines genetic information & 12.1 & 19.2 & 68.7 \\
\hline States that genetic information can be considered a pre-existing condition & 9.4 & 18.9 & 71.6 \\
\hline \multicolumn{4}{|l|}{ California state laws regarding the use of genetic information as it relates to health insurance } \\
\hline Prevent genetic information from being used as a criterion for insurance coverage decisions & 33.0 & 5.5 & 61.5 \\
\hline Provide privacy of "genetic information" to people covered by group health insurance & 34.6 & 5.0 & 60.4 \\
\hline Provide privacy of "genetic information" to people covered by individual health insurance & 25.1 & 9.8 & 65.1 \\
\hline $\begin{array}{l}\text { Prohibit insurers from using clinical signs of a disease, whether due to genetic predisposition } \\
\text { or not, as a source of underwriting information }\end{array}$ & 18.3 & 22.1 & 59.6 \\
\hline Require written consent for disclosure of genetic test results to any third party by a health plan & 51.0 & 3.4 & 45.6 \\
\hline
\end{tabular}

Bold text indicates correct answer.

Of the $55 \%$ who did not refer, $0.7 \%$ did not refer because they perform genetic counseling/testing for their patients themselves.

Stepwise logistic regression analyses identified a positive attitude toward genetic testing as the strongest predictor of referral (Table 4). For each one point increase in attitude, the likelihood of referral increased 3.5 times (odds ratio: 3.55 [95\% confidence interval: 2.24-5.63], $P<0.001$ ). The higher the belief in GD, the less likely a participant was to refer, whereas more knowledge of GD law was associated with both comfort recommending and actual referral. The higher the percent of underserved patients a respondent had, the less likely they were to refer their patients for genetic counseling and testing.

\section{DISCUSSION}

Genetic testing for predisposition to common cancers, such as breast and colorectal cancer, has been available clinically for more than 10 years. This testing is increasingly supported by evidence-based documentation on the efficacy of screening and risk reduction interventions. ${ }^{26-29}$ As such, GCRA is considered standard of care for numerous heritable cancer syndromes. ${ }^{2,24}$ Nonetheless, potential barriers to participation include high cost of genetic tests and inconsistent insurance coverage, limited lay and professional knowledge about clinical cancer genetics referral guidelines, and fears about potential GD among patients ${ }^{6,30-32}$ and clinicians. ${ }^{19,20,22,33}$ Results of a phone survey at Washington State indicated that $60 \%$ of 1450 adults were concerned about GD. ${ }^{21}$ In a survey of 163 cancer genetic specialists choices for care if they were at $50 \%$ risk of carrying a hereditary predisposition to cancer, $68 \%$ stated they would not bill their insurance company because of concerns about GD. ${ }^{22}$ Although a recent follow-up survey of cancer genetic counselors indicated less concern about GD and more willingness to use health insurance for genetic testing, ${ }^{34}$ we found that nongenetics clinicians still harbor significant GD concerns and that these concerns influence referral practice. 


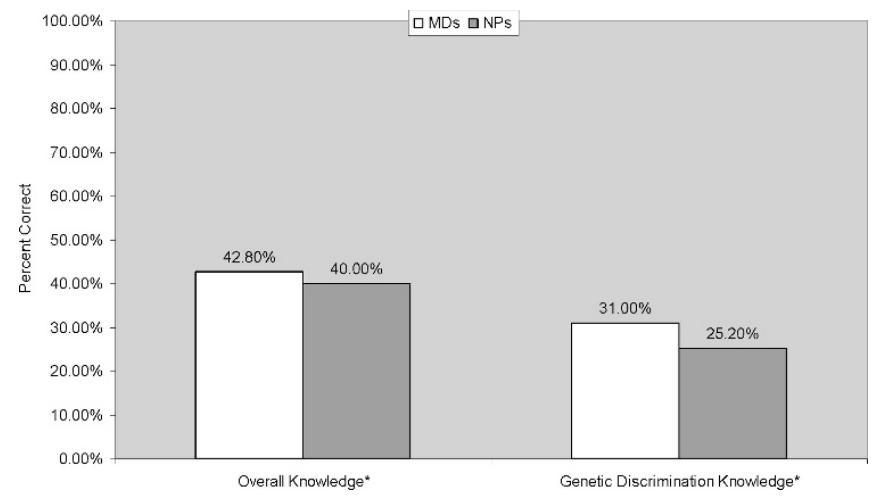

Fig. 1. Knowledge and profession. $P<0.001$.

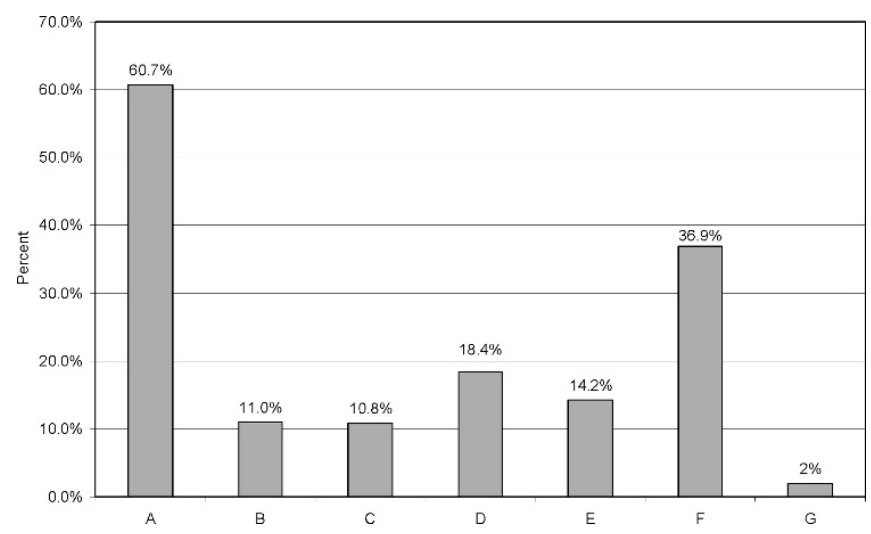

Fig. 2. Reasons for not referring patients for genetic cancer risk assessment. A, No opportunity. B, Clinician concerned about health insurance discrimination. C, Patient was concerned about health insurance discrimination. D, No insurance or insurance did not cover. E, No local genetic counseling services. F, Referral process unclear. G, I do not endorse the use of genetic testing.

To our knowledge, this is the first comprehensive survey of knowledge and perceptions about GD and protective legislation among primary care and specialty clinicians who directly influence access to GCRA. Despite an overall favorable view of the potential benefits genetic testing may have on medical management for patients and family members, there were concerns about possible GD and inadequate knowledge about laws prohibiting the use of genetic information to determine health insurance eligibility. Clinicians also perceived that their patients were concerned about the potential for GD. Nedelcu et al. ${ }^{19}$ observed similar levels of GD concern in 271 clinicians before their attendance at cancer genetic seminars, with 52\% believing that mutation carriers have difficulty obtaining health insurance. Concerns about GD were also reported by Freedman et al., ${ }^{20}$ who surveyed 1251 US physicians from 1999 to 2000, and a 1997 survey of Alabama primary care physicians revealed concerns that genetic testing could lead to employment and insurance discrimination. ${ }^{35}$ However, specific knowledge of protective legislation was not surveyed in the latter two studies.

Although clinicians in our study had greater knowledge of federal law (HIPAA) than California laws, the overall level of knowledge of GD protective legislation and of cancer genetics principles was low. We believe that the respondents are adequately representative of the clinicians sampled, because we minimized responder bias by using a prequalification postcard that described the survey topic as cancer genetics with no allusion to GD, and the specialty and practice-type distributions of respondents and nonrespondents were comparable. However, low response rates to physician surveys has been a concern, ${ }^{36-38}$ and is echoed here, tracking recent trends toward reduced time per patient and increased paperwork.

Over sampling individuals in urban cores where cancer genetics services are often located allowed greater opportunity to observe whether knowledge and perceptions of GD influence referral behavior. Respondents with a higher percentage of underserved patients had lower referral rates. This likely reflects a disparity in access to care, in that public health coverage for indigent patients (e.g., Medicaid) does not usually provide coverage for genetic testing. We and others have demonstrated that underserved populations are willing to participate in GCRA and/or cancer screening and prevention activities absent the systemic barrier. ${ }^{39-41}$

It is unclear how effective existing and emerging federal and state legislation will prove to be. Nonetheless, to date there are few documented incidents of health insurance discrimination in the cancer genetics setting. HIPAA prohibits insurers from charging different individual premiums within a group plan

Table 4

Logistic regression of (1) behavioral intent; and (2) behavior on explanatory variables

\begin{tabular}{|c|c|c|c|c|c|c|}
\hline \multirow[b]{2}{*}{ Variables } & \multicolumn{3}{|c|}{$\begin{array}{l}\text { Logistic regression } 1 \\
\text { Comfortable recommending genetic counseling }\end{array}$} & \multicolumn{3}{|c|}{$\begin{array}{l}\text { Logistic regression } 2 \\
\text { Has referred for genetic counseling }\end{array}$} \\
\hline & Wald statistic $(P)$ & Odds ratio & $95 \% \mathrm{CI}$ & Wald statistic $(P)$ & Odds ratio & $95 \% \mathrm{CI}$ \\
\hline$\%$ Underserved population in practice & & & & $6.62(0.01)$ & 0.72 & $0.557-0.924$ \\
\hline Age & $10.27(0.001)$ & 1.022 & $1.009-1.036$ & $2.59(0.108)$ & 1.02 & $0.997-1.04$ \\
\hline Profession (MD vs. NP) & $23.56(<0.001)$ & 0.511 & $0.390-0.670$ & $15.89(<0.001)$ & 2.24 & $1.51-3.34$ \\
\hline Specialty (PCC vs. other) & & & & $1.47(0.226)$ & 1.51 & $0.775-2.94$ \\
\hline Knowledge of genetic discrimination law & $28.94(<0.001)$ & 1.18 & $1.11-1.25$ & $13.21(<0.001)$ & 1.17 & $1.08-1.28$ \\
\hline Attitudes toward genetic testing & $68.20(<0.001)$ & 4.09 & $2.93-5.71$ & $28.99(<0.001)$ & 3.55 & $2.24-5.63$ \\
\hline Beliefs about genetic discrimination & & & & $4.06(0.044)$ & 0.72 & $0.518-0.991$ \\
\hline
\end{tabular}


and states that genetic information cannot be used to determine eligibility, and that genetic information cannot be viewed as a pre-existing condition (".. in the absence of a diagnosis of the condition related to such information"). However, HIPAA does not prohibit access by insurers to genetic information, prohibit the insurer from demanding genetic testing as a condition of coverage, protect against group rate hikes or provide protection outside the group market (individual policies are not covered).

Since 1991, at least 47 states have enacted some form of legislation addressing genetic issues. ${ }^{42}$ Protective legislation in California, some of the most comprehensive in the nation, may not be representative of law in many other states. Consequently, our results may not be entirely generalized for other states. The knowledge deficits and perceptions we observed may be greater in states with more recently enacted or less well-publicized laws. It is important to recognize as well that the legislated protections apply exclusively to individuals with asymptomatic genetic traits. The problem of potential adverse action by insurers because of new symptomatic disease is common to health care coverage in general. It would be very challenging to discern any incremental effect of the genetic information superimposed on the primary issue of a symptomatic cancer.

Although the majority of clinicians in our study indicated that they were comfortable referring patients for genetic counseling, less than half had referred and few had provided genetic testing for their patients themselves. Wideroff et al. ${ }^{43}$ also reported that most clinicians referred patients rather than ordering genetic tests themselves.

The majority of clinicians in this study believed they could recognize hereditary cancer patterns, but more than twothirds were not able to identify appropriate cases for referral. This raises concerns about the quality of referrals and possible under-recognition of patients appropriate for GCRA. Previous studies highlighted important gaps in physician/nurse knowledge regarding genetic testing and cancer genetics. ${ }^{20,44,45}$ Moreover, a survey of patients revealed that they often perceive their primary care providers as having limited knowledge regarding genetics, which may discourage patients from discussing genetic testing with them. ${ }^{46}$

Although not addressed in this study, there are also significant concerns about privacy of genetic information. Few state laws, outside California and Minnesota, prohibit disclosure of genetic information; even there, following the provisions is difficult in actual practice. These issues highlight the need for comprehensive legislation prohibiting the misuse of that information.

Overall, our results and the extant literature indicate that knowledge gaps and perceptions are barriers to GCRA referrals. Clinicians were concerned about the potential for GD and were ill-informed about existing federal and California state protective laws. The comments demonstrate a need for and interest in more educational opportunities in this area. More comprehensive federal law, increased education for clinicians about the use of GCRA, referral guidelines, and legal protec- tions against GD should enhance access to risk-appropriate cancer screening and prevention. ${ }^{47,48}$

The GINA (Genetic Information Nondiscrimination Act) of 2008 was recently approved by the House of Representatives by a vote of 414 to 1 and passed unanimously by the Senate. President Bush signed GINA into law on May 21, 2008, with most provisions taking effect in 6-12 months. GINA generally stipulates the following:

1. GINA prohibits employers from requesting, requiring, or purchasing genetic information; requiring an individual to take a genetic test as a condition of employment; or discriminating on the basis of "genetic information." This term is defined as "information about an individual's genetic tests, the genetic tests of family members, or the occurrence of a disease in family members of the individual."

2. GINA does not apply to individuals who have a "manifestation of a disease, disorder, or pathologic condition." These terms are not defined.

3. GINA prohibits health insurance companies from denying or canceling coverage based on genetic information. However, GINA does not apply to life insurance, disability insurance, or long-term care insurance. However, because GINA does not provide comprehensive protection outside the health insurance market against GD, it remains unclear whether GINA will affect the willingness of at-risk individuals to undergo genetic testing.

However, this new law provides a federal framework for protections based on a genetic predisposition for a disease, instead of the patchwork of state laws throughout the country. Congress found that "while many states have enacted some type of genetic nondiscrimination law, these laws vary widely with respect to their approach, application, and level of protection. Congress has collected substantial evidence that the American public and the medical community find the existing patchwork of State and Federal laws to be confusing and inadequate to protect them from discrimination." The uncertainty of how test results might be used has led many to refuse testing because of fear of employers using the genetic test results against them or of insurance companies denying coverage.

And, as GINA further states, "[g]enetic testing can allow individuals to take steps to reduce the likelihood that they will contract a particular disorder. New knowledge about genetics may allow for the development of better therapies that are more effective against disease or have fewer side effects than current treatments."

The mapping of the human genome shows great promise for making medical care more preventive and effective and for new treatments to be developed. GINA, by providing protection in both the group and individual health insurance markets and in the employment arena, shows great promise to provide the protections that the people need to have confidence going forward. Nonetheless, it will remain to be seen how much protection GINA provides once it goes into effect. As highlighted in this study, we believe education for clinicians on both exist- 
ing and new legislation and on cancer genetics practice guidelines will result in more confident and appropriate usage of GCRA and testing, which will lead to risk-appropriate cancer screening and prevention measures in high-risk individuals.

\section{ACKNOWLEDGMENTS}

This project was supported in part by funds received from the State of California, Department of Health Services, Cancer Research Program, and by Grant Number R03 HG002846 from National Human Genome Research Institute.

We thank Janelle Hilario for assistance with manuscript submission; Lei Chen, Jenny Chuang, and Joycelynne Palmer for assistance with construction of the on-line database; Christine Gonzalez for assistance with recruitment of Latino physicians, facilitating mailings to the CaLMA membership; and survey respondents.

\section{References}

1. Daly MB, Axilbund JE, Bryant E, et al. Genetic/familial high-risk assessment: breast and ovarian. J Natl Compr Canc Netw 2006;4:156-176.

2. American Society of Clinical Oncology. American society of clinical oncology policy statement update: genetic testing for cancer susceptibility. J Clin Oncol 2003;21: 2397-2406.

3. Billings PR, Kohn MA, de Cuevas M, Beckwith J, Alper JS, Natowicz MR. Discrimination as a consequence of genetic testing. Am J Hum Genet 1992;50:476-482.

4. Hall MA, McEwen JE, Barton JC, et al. Concerns in a primary care population about genetic discrimination by insurers. Genet Med 2005;7:311-316.

5. Hall MA, Rich SS. Patients' fear of genetic discrimination by health insurers: the impact of legal protections. Genet Med 2000;2:214-221.

6. Rose AL, Peters N, Shea JA, Armstrong K. Attitudes and misconceptions about predictive genetic testing for cancer risk. Community Genet 2005;8:145-151.

7. Lapham EV, Kozma C, Weiss JO. Genetic discrimination: perspectives of consumers. Science 1996;274:621-624.

8. Kass NE, Hull SC, Natowicz MR, et al. Medical privacy and the disclosure of personal medical information: the beliefs and experiences of those with genetic and other clinical conditions. Am J Med Genet A 2004;128A:261-270.

9. Hadley DW, Jenkins J, Dimond E, et al. Genetic counseling and testing in families with hereditary nonpolyposis colorectal cancer. Arch Intern Med 2003;163:573-582.

10. Health Insurance Portability and Accountability Act of 1996. Public law 104-191. US Statut Large 1996;110:1936-2103.

11. Office for Civil Rights, HHS. Standards for privacy of individually identifiable health information. Final rule. Fed Regist 2002;67:53181-53273.

12. Legislatures NCoS. Genetics and Health Insurance State Anti-Discrimination Laws Genetic Technologies Project. NCSL Genetics Tables 2007 [cited February 13, 2008]. Available at: http://www.ncsl.org/programs/health/genetics/ndishlth.htm.

13. Compliance Manual. Commission TUSEEO. 1995:902-945.

14. Burlington Northern settles suit over genetic testing. New York Times April 19, 2001.

15. Reilly PR. Genetic risk assessment and insurance. Genet Test 1998;2:1-41.

16. Volpe LC. Genetic testing and health insurance practices: an industry perspective. Genet Test 1998;2:9-12.

17. Pollitz K, Peshkin BN, Bangit E, Lucia K. Genetic discrimination in health insurance: current legal protections and industry practices. Inquiry 2007;44:350-368.

18. Wingrove K, Norris J, Barton P, Hagerman R. Experiences and attitudes concerning genetic testing and insurance in a Colorado population: a survey of families diagnosed with fragile X syndrome. Am J Med Genet 1996;64:378-381.

19. Nedelcu R, Blazer KR, Schwerin BU, et al. Genetic discrimination: the clinician perspective. Clin Genet 2004;66:311-317.

20. Freedman AN, Wideroff L, Olson L, et al. US physicians' attitudes toward genetic testing for cancer susceptibility. Am J Med Genet A 2003;120A:63-71.

21. Ulrich CM, Kristal AR, White E, Hunt JR, Durfy SJ, Potter JD. Genetic testing for cancer risk: a population survey on attitudes and intention. Community Genet 1998; $1: 213-222$.

22. MatloffET, Shappell H, Brierley K, Bernhardt BA, Mckinnon W, Peshkin BN. What would you do? Specialists' perspectives on cancer genetic testing, prophylactic surgery, and insurance discrimination. J Clin Oncol 2000;18:2484-2492.
23. Weitzel JN. Genetic cancer risk assessment: putting it all together. Cancer 1999; 86(11 Suppl):2483-2492.

24. Daly MB, Axibund JE, Bryant E, et al. NCCN practice guidelines in oncology: ge netic/familial high-risk assessment: breast and ovarian. 2007. Available at: http:// www.nccn.org/professionals/physician_gls/PDF/genetics_screening.pdf. Accessed March 22, 2007.

25. Dillman DA, Christensen JA, Carpenter EH, Brooks RM. Increasing mail questionnaire response: a four state comparison. Am Sociol Rev 1974;39:746-755.

26. Jarvinen HJ, Aarnio M, Mustonen H, et al. Controlled 15-year trial on screening for colorectal cancer in families with hereditary nonpolyposis colorectal cancer. Gastroenterology 2000;118:829-834.

27. Rebbeck TR, Friebel T, Lynch HT, et al. Bilateral prophylactic mastectomy reduces breast cancer risk in BRCA1 and BRCA2 mutation carriers: the PROSE study group. J Clin Oncol 2004;22:1055-1062.

28. Rebbeck TR, Lynch HT, Neuhausen SL, et al. Prophylactic oophorectomy in carriers of BRCA1 or BRCA2 mutations. N Engl J Med 2002;346:1616-1622.

29. Warner E, Plewes DB, Hill KA, et al. Surveillance of BRCA1 and BRCA2 mutation carriers with magnetic resonance imaging, ultrasound, mammography, and clinical breast examination. JAMA 2004;292:1317-1325.

30. Lee SC, Bernhardt BA, Helzlsouer KJ. Utilization of BRCA1/2 genetic testing in the clinical setting: report from a single institution. Cancer 2002;94:1876-1885.

31. Peterson EA, Milliron KJ, Lewis KE, Goold SD, Merajver SD. Health insurance and discrimination concerns and BRCA1/2 testing in a clinic population. Cancer Epidemiol Biomarkers Prev 2002;11:79-87.

32. Thompson HS, Valdimarsdottir HB, Duteau-Buck C, et al. Psychosocial predictors of BRCA counseling and testing decisions among urban African-American women. Cancer Epidemiol Biomarkers Prev 2002;11:1579-1585.

33. Blazer KR, Grant M, Sand SR, MacDonald DJ, Uman GC, Weitzel JN. Effects of a cancer genetics education programme on clinicians knowledge and practice. $J \mathrm{Med}$ Genet 2004;41:518-522.

34. Huizenga CR, Lowstuter K, Banks KC, et al. Genetic discrimination: a survey of cancer genetics professionals' knowledge, attitudes, and practices. In: 57th Annual American Society of Hum Genet Meeting, San Diego, CA, 2007.

35. Acton RT, Burst NM, Casebeer L, et al. Knowledge, attitudes, and behaviors of Alabama's primary care physicians regarding cancer genetics. Acad Med 2000;75: $850-852$.

36. Maheux B, Legault C, Lambert J. Increasing response rates in physicians' mail surveys: an experimental study. Am J Public Health 1989;79:638-639.

37. Sobal J, Valente CM, Muncie HL Jr, Levine DM, Deforge BR. Physicians' belief about the importance of 25 health promoting behaviors. Am J Public Health 1985; 75:1427-1428.

38. Cartwright A. Professionals as responders: variations in and effects of response rates to questionnaires, 1961-77. BMJ 1978;2:1419-1421.

39. Emmons KM, Stoddard AM, Fletcher R, et al. Cancer prevention among working class, multiethnic adults: results of the healthy directions-health centers study. Am J Public Health 2005;95:1200-1205.

40. Ricker C, Lagos V, Feldman N, et al. If we build it. Will they come?-establishing a cancer genetics services clinic for an underserved predominantly Latina cohort. J Genet Couns 2006;15:505-514.

41. Ricker CN, Hiyama S, Fuentes S, et al. Beliefs and interest in cancer risk in an underserved Latino cohort. Prev Med 2007;44:241-245.

42. Jaeger AS, Mulholland WF II. Impact of genetic privacy legislation on insurer behavior. Genet Test 2000;4:31-42.

43. Wideroff L, Freedman AN, Olson L, et al. Physician use of genetic testing for cancer susceptibility: results of a national survey. Cancer Epidemiol Biomarkers Prev 2003; 12:295-303.

44. Wideroff L, Vadaparampil ST, Greene MH, Taplin S, Olson L, Freedman AN. Hereditary breast/ovarian and colorectal cancer genetics knowledge in a national sample of US physicians. J Med Genet 2005;42:749-755.

45. Maradiegue A, Edwards QT, Seibert D, Macri C, Sitzer L. Knowledge, perceptions, and attitudes of advanced practice nursing students regarding medical genetics. J Am Acad Nurse Pract 2005; 17:472-479.

46. Harvey EK, Fogel CE, Peyrot M, Christensen KD, Terry SF, McInerney JD. Providers' knowledge of genetics: a survey of 5915 individuals and families with genetic conditions. Genet Med 2007;9:259-267.

47. Beckman M. Genetic nondiscrimination legislation could improve cancer preven tion-if it passes. J Natl Cancer Inst 2007;99:993-995.

48. Establishing federal protections against genetic discrimination [position paper] Philadelphia: American College of Physicians; 2008. (Available from American College of Physicians, 190 N. Independence Mall West, Philadelphia, PA 19106). 